\title{
ANÁLISIS DE LA ACTIVIDAD Y PRESENCIA EN FACEBOOK Y OTRAS REDES SOCIALES DE LOS PORTALES TURÍSTICOS DE LAS COMUNIDADES AUTÓNOMAS ESPAÑOLAS
}

\author{
Claudia Marcela Giraldo Cardona \\ Soledad María Martínez María-Dolores \\ Universidad Politécnica de Cartagena. España
}

\section{RESUMEN}

Las redes sociales son una herramienta muy útil para la promoción de servicios, productos y destinos en el sector turístico. Por ello, teniendo en cuenta el elevado crecimiento de usuarios de redes sociales durante los últimos años, el objetivo de este estudio es analizar la actividad de las Comunidades Autónomas Españolas en las mismas. Para ello, a través del modelo PRGS (Presencia, Respuesta, Generación y Sugerencia), medimos el comportamiento y la actividad que las marcas turísticas de 11 Comunidades Autónomas Españolas llevan a cabo en las redes sociales, fijándonos especialmente en Facebook por la relevancia que tiene en este sector.

Palabras clave: Facebook, Marcas Turísticas, Modelo PRGS, Portales Turísticos, Redes Sociales, Turismo.

\section{Analysis of the activity and presence in Facebook and others social networks of the} tourism webs of the Spanish Autonomous Communities

\section{ABSTRACT}

Social networks are a very useful tool for the promotion of services, products and destinations in the tourism sector. Therefore, given the high growth of users of social networks during the last years, the aim of this paper is to analyze the activity of the autonomous

Recibido: 8 de septiembre de 2015

Devuelto para su revisión: 5 de febrero de 2016

Aceptado: 5 de abril de 2016

Departamento de Métodos Cuantitativos e Informáticos. Facultad Ciencias de la Empresa. Universidad Politécnica de Cartagena. C/ Real, 3.30201 CARTAGENA. Murcia (España).E-mail: clao84@hotmail.com, soledad. martinez@upct.es) 
communities in social networks. To this end, through the model PRGS (Presence, Response, Generation and Suggestion), we measure the behavior and activity that the tourism brands of 11 Spanish autonomous communities are carrying out in social networks, mainly on Facebook.

Keywords: Facebook, tourism brands, social network sites, tourism webs, tourism.

\section{INTRODUCCIÓN}

La aparición de las redes sociales ha fomentado el comportamiento de los consumidores de conversar entre sí, comparar y recomendar productos y servicios, lo cual ha creado la necesidad para muchas empresas de integrarlas como parte de su estrategia comercial. En los últimos años, el uso de las redes sociales en el ámbito del comercio electrónico se ha incrementado al ofrecer a las empresas la oportunidad de establecer relaciones con sus clientes potenciales.

El sector turístico es un sector muy cambiante, y está demostrado que los participantes de las redes sociales son posibles consumidores, y es por ello que el sector, en general, debe de intentar beneficiarse de su uso. Por esta razón el objetivo principal de este estudio es analizar la actividad de las Comunidades Autónomas Españolas en el entorno de las redes sociales.

Para el desarrollo de este artículo, en primer lugar se llevará a cabo una revisión de la literatura sobre turismo, redes sociales y portales y marcas turísticas para, posteriormente, analizar un listado de marcas turísticas de las Comunidades y Ciudades Autónomas Españolas. Una vez analizado el comportamiento y la actividad que éstas llevan a cabo en las redes sociales, se extraerán una serie de conclusiones.

\section{LA MARCA E IMAGEN DE MARCA EN EL SECTOR TURÍSTICO}

El turismo es un sector que ha crecido de manera notoria durante los últimos años, permitiendo a cada país ofrecer y promocionar sus recursos y conseguir con ello, no sólo darse a conocer en todo el mundo sino, además, aumentar su número de visitantes, incentivando el consumo y mejorando así su situación en la economía.

La Organización Mundial del Turismo (OMT, 1995) define al turismo como el conjunto de actividades que realizan las personas durante sus viajes y estancias en lugares distintos a su entorno habitual, por un período de tiempo consecutivo inferior a un año, con fines de ocio, negocios u otras actividades.

España es una potencia en turismo a nivel mundial que actualmente, según el último informe de la OMT, ocupa el tercer puesto del mundo en número de turistas extranjeros (OMT, 2014). Según datos proporcionados por la Encuesta de Movimientos Turísticos en Fronteras (FRONTUR), difundida por el Ministerio de Industria, Energía y Turismo, la mayor afluencia de turistas proviene en gran medida de Reino Unido, Alemania y, especialmente, de Francia y los destinos que principalmente reciben un número de estos son Andalucía, Cataluña y sobre todo Canarias. 
La creación de la imagen de marca, en un sector turístico tan competitivo como el actual, surge como consecuencia de un esfuerzo importante para dar respuesta a las nuevas exigencias del mercado, dando al producto o servicio atributos únicos que le permita diferenciarse de los competidores.

Cada vez más, las experiencias positivas de los turistas en el destino buscan no sólo la repetición de visitas al mismo, sino además, la recomendación a los amigos, familiares y contactos de las redes sociales. La imagen es clave para atraer a los turistas, es un elemento crítico en la elección del proceso de destino, con independencia de si es representativa de lo que un lugar tiene que ofrecer (Crompton, 1992).

En este sentido, consolidar la marca y posicionar su imagen en la mente del consumidor requiere de tiempo y mucha dedicación, ya que la percepción que tiene el cliente del producto o servicio es importante. Por este motivo se debe cuidar la marca y hacer un constante análisis, para evaluar si está representando realmente la imagen de marca que se desea mostrar o si no está comunicado lo que se pretende, definir los objetivos y estrategias a llevar a cabo para posicionarla en la mente del consumidor.

\subsection{Concepto de marca e imagen de marca}

De acuerdo con la definición de la Asociación Americana de Marketing, una marca es un nombre, término, señal, símbolo o diseño, o una combinación de todos ellos, que busca identificar los bienes y servicios de un vendedor, o un grupo de vendedores, y diferenciarlos de los de sus competidores. Por otro lado, la Asociación Nacional para la defensa de la Marca (ANDEMA, 2001), define la marca como un signo distintivo, cuya principal función es diferenciar en el mercado a los productos y/o servicios de una empresa de los de sus competidores.

Así, Doyle (2003) ha identificado cinco características principales que poseen las marcas exitosas, las cuales responden a las actividades que se hacen para desarrollarlas eficazmente en el tiempo y en el espacio, y que pueden resumirse como:

- Un producto de calidad. La experiencia satisfactoria en el uso es el determinante más importante del éxito de una marca. La calidad es indispensable. Si la calidad de una marca se deteriora, los clientes cambiarán a las marcas de la competencia, y el posicionamiento de la marca se verá disminuido.

- Posicionamiento único. Si la marca no es innovadora, debe tener un concepto de posicionamiento único que la diferenciará de sus competidoras.

- Ser el primero en el mercado. Es necesario innovar para facilitar la penetración en el mercado. Es más fácil ocupar una posición en la mente de los consumidores cuando la marca no tiene competidores, y llegar al mercado con una propuesta innovadora.

- Programa de comunicación fuerte. Para que una marca sea exitosa necesita de un apoyo fuerte en publicidad, ventas y promoción. Así, puede comunicar la proposición de la marca y crear una identidad fuerte de la misma.

- Tiempo y consistencia. Construir una marca fuerte lleva tiempo, y se requiere de una buena inversión para mantener, rejuvenecer y/o reposicionarla en un entorno cambiante. 
El concepto de marca en el sector turístico se encuentra en un proceso complejo de adaptación para el consumidor. Al tratarse de un servicio, por tanto intangible, el turista no tiene capacidad de probar un destino hasta que no disfruta de él (Eby et al., 1999). Para Blain et al. (2005), la marca turística es el conjunto de actividades de marketing encaminadas a apoyar la creación de un nombre, símbolo o cualquier otro gráfico que identifica y diferencia un destino, que transmite de forma continua la expectativa de una experiencia asociada únicamente a ese lugar, que sirven para consolidar y reforzar la conexión emocional entre el visitante y el destino, y que reduce costes y riesgos para el consumidor. Finalmente, Huertas (2014) define la marca turística como aquella que se compone de un nombre, un logotipo, unos símbolos y unos valores que se tratan de asociar a un territorio representando su identidad, con el objetivo de crear un posicionamiento y una visión positiva del destino en la mente de sus públicos.

Respecto a la imagen de marca, ésta se define como la percepción global que los consumidores desarrollan sobre ella (Ordozgoiti y Pérez, 2003).

Lambin et al. (2009), sostienen que la imagen de marca puede definirse como el conjunto de representaciones mentales, tanto cognitivas como afectivas, que una persona o un grupo de personas tiene frente a una marca o una empresa. Estos autores realizan la siguiente distinción entre tres niveles de análisis de imagen de marca, los cuales se detallan a continuación:

1. La imagen percibida, es decir, cómo las personas ven y perciben la marca: una perspectiva desde afuera hacia adentro basada en entrevistas de campo dentro del mercado o segmento de referencia.

2. La imagen real o la realidad de la marca. La perspectiva desde adentro hacia adentro, basada en las fortalezas y debilidades identificadas por la empresa a través de la auditoría interna.

3. La imagen deseada (su identidad) o la forma en que la gestión de marca desea que la marca sea percibida por el segmento objetivo como resultado de una decisión de posicionamiento o identidad de marca.

En el sector turístico, Murphy et al., (2000) afirman que la imagen incluye la percepción personal de los múltiples componentes del destino turístico. Por otra parte Bigné et al., (2001) aportan que la imagen de un destino turístico es la percepción global del turista acerca del lugar. Siguiendo en esta línea Beerli y Martín (2004), afirman que la imagen de un destino turístico puede ser definida como la forma en que el turista percibe los atributos físicos o características de una zona turística.

Por otro lado, Blain et al. (2005), aportan una definición de la imagen de destino como conjunto de diferentes acciones de marketing encaminadas a:

1. Ayudar a la creación de un nombre junto a su logotipo y marca propia, que lo identifique y distinga claramente de otros destinos.

2. Crear un conjunto de expectativas favorables ante una experiencia de viaje única.

3. Consolidar y perdurar la unión emocional entre el turista y el destino.

4. Centrar la búsqueda de consumidores potenciales, disminuyendo costes y aumentando la rentabilidad de las acciones de marketing. 
Así pues, teniendo en cuenta las definiciones anteriores, la imagen de marca de un destino turístico puede considerarse una impresión general o el conjunto de impresiones individuales del turista sobre un determinado destino (Millet, 2011).

Entender de forma adecuada la imagen de marca y las fortalezas y debilidades percibidas es un prerrequisito indispensable para plantear cualquier estrategia y plataforma de comunicación en una empresa. En el sector turístico resulta esencial una buena gestión de la marca y su imagen, cuyo objetivo principal consiste en que ésta se posicione en la mente del consumidor ya que éste no sólo busca un producto o servicio específico sino un nuevo atributo, la experiencia, y es aquí donde los empresarios deben plantearse estrategias para satisfacer la nueva demanda del cliente (Giraldo y Martínez, 2015).

\subsection{Importancia de la marca y de la imagen de marca en el sector turístico}

En una industria turística rodeada de cambios constantes, un desafío clave para las empresas es poner en valor su marca; la gran mayoría de los turistas elige sus destinos por la marca e imagen que percibe de ellos. Así, muchos lugares buscan implantar técnicas de promoción a través de la creación de imagen de marca con el fin de diferenciar su identidad y subrayar el carácter único de su destino (Folgado et al., 2011).

Las marcas turísticas buscan un concepto de imagen diferenciada, como respuesta a los deseos de una parte del mercado que les aporte un valor añadido específico y único, creando sinergias y negocio para una determinada zona (Memelsdorff, 1998).

Una marca turística bien gestionada puede aportar numerosas ventajas, entre ellas la posibilidad de competir con otros destinos de igual a igual, además ayuda a reforzar la imagen de los destinos maduros ya que les permite competir con los emergentes (Hosteltur, 2008). Así, en el sector turístico, las empresas necesitan desarrollar una marca fuerte para sobrevivir en un entorno tan competitivo con la intención de despertar en el consumidor una concienciación, una compra y una lealtad hacia el producto o servicio (Martorell y Servera, 2004).

La imagen de marca cumple un papel fundamental en el éxito de los destinos turísticos, ya que ejerce una fuerte influencia en el comportamiento del consumidor en el ámbito turístico. Los turistas suelen tener un conocimiento limitado de los destinos turísticos que no han visitado y es aquí donde la imagen cumple una importante función en la medida de que aquellos destinos con imágenes más fuertes, positivas, diferenciadas y reconocibles tienen más posibilidades de ser elegidos por parte de los turistas. Además, la imagen percibida del destino después de la visita también influye en la satisfacción del turista y de sus intenciones de volver al destino en un futuro (Beerli y Martín, 2002).

\subsection{La marca e imagen de marca del sector turístico a través de las redes sociales}

En el sector turístico, la lealtad del cliente es difícil de conseguir, incluso cuando éstos están realmente satisfechos con la experiencia de su viaje ya que la curiosidad hace que se vean atraídos hacia otras alternativas (Martorell y Servera, 2004).

Piñeiro (2012), afirma que una empresa puede utilizar las redes sociales para muchas cosas, tanto para realizar una investigación de mercado como para ofrecer atención al 
cliente pero en la actualidad una de las principales motivaciones de las marcas es mejorar su imagen. Por ello, recomienda las siguientes acciones que ayudarán a transmitir una buena imagen en las redes sociales.

- Aportar valor. Aportar contenido de valor, ayudar y ofrecer un servicio real a través de las redes sociales es una garantía. Si el usuario percibe valor en el contenido, percibe valor en la marca.

- Centrarse en una comunidad. Para que en el muro existan comentarios y participación real lo mejor es no intentar abarcar todos los tipos de usuarios y centrarse en una comunidad concreta. De esta forma será mucho más sencillo desarrollar contenidos de su interés y se conseguirá obtener el denominado engagement, que consiste en el grado en que un consumidor interactúa con la marca. Es decir, se trata de construir relaciones sólidas, fuertes, recíprocas, permanentes y duraderas con el público (Jiménez, 2012).

- Darle un papel protagonista al usuario. Los medios sociales son canales de interacción. Para causar una buena sensación y mejorar la experiencia es muy recomendable que el usuario sea consciente de lo que se espera de él en las redes, el papel que desempeña e incluso sugerirle cosas que puede hacer en la red.

- Responder siempre rápido y bien. Las redes sociales dan visibilidad a la atención al cliente. Aquellos que ya han comprado un producto tendrán una mejor experiencia si se les ayuda y por tanto recomendarán el producto y la empresa. Aquellos que están comparando diferentes alternativas antes de comprar se decidirán por la empresa que mejor trate a sus clientes en las redes sociales.

- Cuidar la reputación. Lo que los usuarios dicen de una marca es más importante que lo que la propia marca dice. Los comentarios de los clientes generan más confianza que los que realiza la propia empresa. Por este motivo es fundamental analizar lo que se está diciendo de la marca y compararlo con la competencia. A partir de ahí centrar los esfuerzos en conseguir que los propios usuarios recomienden más la marca, aumenten los comentarios positivos y se minimice el impacto de los negativos.

Mostrar que la empresa está viva y es moderna es una de las principales razones por la que empresarios y directivos de grandes y pequeñas empresas deciden apostar por plataformas como Facebook, Twitter o LinkedIn entre otras, por ello resulta importante transmitir una buena imagen en las redes sociales y así conquistar al consumidor social.

\section{REDES SOCIALES EN LOS PORTALES TURÍSTICOS}

\subsection{Concepto y principales Redes Sociales}

De acuerdo con Cross y Parker (2004), una red social es una estructura social compuesta por individuos u organizaciones, llamadas nodos, que están relacionados o conectados entre sí y pueden ser representadas por arcos que simbolizan diferentes tipos de relaciones entre los nodos, como la amistad, la dependencia funcional o las relaciones en términos de creencias, conocimientos o el nivel social. 
Fernández (2009), distingue entre redes sociales analógicas o redes sociales offline, que son aquellas en las que las relaciones sociales, con independencia de su origen, se desarrollan sin mediación de aparatos o sistemas electrónicos, y entre las redes sociales digitales o redes sociales online o virtuales, aquellas que tienen su origen y se desarrollan a través de medios electrónicos.

De las diferentes tipologías existentes de redes sociales, nos centraremos en las virtuales que son las utilizadas en nuestro análisis. Las redes sociales virtuales propician la interacción de miles de personas en tiempo real (Fernández, 2009) y se han convertido en herramientas importantes de comunicación de masas, en especial para difundir noticias e influenciar a otros (Boyd y Ellison, 2007).

Boyd y Ellison (2007), definen una red social virtual como un servicio en web que permite a los usuarios:

1. definir un perfil personal,

2. relacionar estos perfiles con una lista de otros perfiles que pertenecen a individuos con los que tienen algún tipo de relación social, y

3. ver los perfiles vinculados a sus conexiones, de forma recursiva.

Así, las redes sociales virtuales son espacios en internet donde los usuarios pueden crear perfiles y se pueden conectar con otros usuarios para crear una red personal (Liberos et al, 2010).

Respecto a las principales Redes Sociales, existen diversos estudios en los que se analiza el uso de redes sociales en España y en ellos, se pone de manifiesto cuáles son las principales redes sociales en términos de número de empresas usuarias (Fundación Telefónica, 2014), número de usuarios y nivel de actividad en redes sociales (IAB, 2014). En dichos estudios se observa que las redes sociales más utilizadas son Facebook y Twitter, seguidas de LinkedIn, YouTube, Pinterest e Instagram.

\subsection{Concepto y marca de los Portales Turísticos de las CCAA}

Un portal podría definirse como un punto de entrada a internet donde se organizan sus contenidos, ayudando al usuario y concentrando servicios y productos, de forma que le permitan realizar cuanto necesite hacer en la red a diario, o al menos que pueda encontrar allí todo cuanto utiliza cotidianamente sin necesidad de salir de dicho sitio (García, 2001).

Aunque originalmente el portal ha pretendido ser la página de entrada a internet, podríamos decir que esta definición se usa para referirse a una página web que hace las funciones de pórtico de entrada a un espacio informativo temático con lo que se pretende homologar el mundo virtual de internet con los espacios sociales y culturales de la vida real. Hablar de portal es mucho más que usar un nombre para definir una forma de estar presente en internet, se trata de una nueva forma de organizarse, un nuevo estilo de trabajo, una nueva filosofía de funcionamiento, en el que se aprovecha el uso de las nuevas tecnologías (Blat et al., 2001).

Así, un portal turístico podría definirse como una plataforma web para dar a conocer y promocionar los recursos de un destino turístico. 
Teniendo en cuenta la continua evolución tecnológica de estos años se ha pasado a un nuevo concepto de portal turístico en los que toma todo el protagonismo la imagen digital frente al texto, ofreciendo los contenidos de las más importantes marcas turísticas de España: Islas Baleares, Islas Canarias, Andalucía, Cataluña, Levante, también del turismo urbano Madrid, Barcelona o Sevilla, turismo interior como Rioja, Navarra o Ribera del Duero, de montaña como Pirineos, o también de destinos poco conocidos en el exterior como Asturias, Extremadura, Castilla la Mancha o Aragón, con contenidos de última generación que mejoran sustancialmente la calidad y variedad de la presentación de las marcas (Pombo, 2012).

Todos estos portales turísticos, integran motores de búsqueda tanto de alojamiento como de vuelos o servicios de los mayoristas del sector, acercando las oferta al propio domicilio del cliente potencial para facilitar la elección y compra del destino y además se caracterizan por tener la innovación y la calidad como objetivo estratégico y una interfaz flexible capaz de adaptarse continuamente a las nuevas tecnologías que van surgiendo y son una respuesta a la creciente tendencia de compra de viajes a través de Internet desde el propio domicilio (Pombo, 2012).

\subsection{Uso de las redes sociales por parte de los Portales Turísticos}

La principal carta de presentación de un destino turístico en Internet es su sitio web oficial. Podríamos entenderlo como la puerta de entrada virtual al destino. En una época en la que son cada vez más los turistas que organizan de manera personal su viaje, un destino que aspira a ser competitivo necesita una presencia en la web y en las redes sociales lo más eficaz y atractiva posible (Fernández et al., 2014).

El sitio web oficial puede resultar clave en el momento de la selección del destino, y el viajero puede optar por visitar un lugar u otro en función de la impresión que el portal turístico le genera. La investigación científica ha demostrado que una experiencia de navegación satisfactoria genera actitudes positivas hacia la marca y, por tanto, intención de compra o, en el caso específico del sector turístico, intención de visitar el destino (Fernández et al., 2014).

La relación entre turismo y redes sociales se ha ido consolidando año tras año. Las redes sociales son una herramienta muy útil para la promoción de servicios, productos y destinos en el sector turístico. La mayoría de los usuarios recurren a las redes sociales en busca de inspiración cuando se trata de decidir dónde pasar unos días de descanso. Así pues, los consumidores confían en las recomendaciones de sus amigos en las redes sociales, familia y/o seguidores antes de decidir dónde ir de vacaciones. Además, una vez realizado el viaje, los usuarios muestran una actitud proactiva en los medios sociales, publicando en sus perfiles sociales algún tipo de información referente a sus vacaciones (Santo, 2014).

A través de las redes sociales, los consumidores toman sus decisiones, basándose no sólo en la información proporcionada por las marcas, sino también en la aportada por otros consumidores (Curty y Zhang, 2011). Las redes sociales permiten que los consumidores den opiniones, puntuaciones, consulten dudas y expongan sus sugerencias sobre los productos o servicios e incluso permiten conocer a otros consumidores con preferencias y gustos similares. Esta interacción entre los clientes lleva a que los usuarios se conviertan en líderes de tendencias de consumo, donde cada usuario es valorado por los demás para crear una reputación o credibilidad determinada (Alvarado, 2012). 
Los turistas se ven influenciados por las opiniones de otros viajeros que se vierten en las diferentes redes sociales (Vermeulen y Seegers, 2009; Gretzel y Yoo, 2008) a la hora de elegir un destino para sus vacaciones. Se trata del conocido "boca a boca" o "bocaoreja" (Word of Mouth) adaptado a internet (Dellarocas, 2003) lo que se ha denominado eWOM (electronic Word of Mouth) (Gruen et al., 2006). El boca-oreja y otras actividades en las redes sociales juegan un papel clave que afecta a la actitud y el comportamiento del usuario (Liang y Turban, 2011). Por este motivo, las empresas deben poner todo su empeño en forjarse una buena reputación digital y gestionar la conversación en entornos colaborativos a propósito de sus marcas con cercanía, transparencia e inmediatez, atendiendo a las críticas para mantener la confianza de sus clientes actuales y no perder clientes potenciales (Castelló y Pino 2015).

En el sector turístico resulta imprescindible, la correcta y profesionalizada gestión de las redes sociales ya que éstas requieren de una atención continua, el contenido publicado debe actualizarse con frecuencia y ser de interés para el público objetivo, se trata pues, de dedicarle tiempo y recursos humanos, gente que las mantengan vivas. En este sentido, juega un papel importante la figura del Community Manager, dicha figura surgió en EE.UU., como el encargado de escuchar a la comunidad online, relacionarse con ella en nombre de la empresa, hacer llegar a su compañía lo que se dice de ella en el mundo digital para identificar amenazas u oportunidades e integrar estos espacios en las estrategias de negocio de la empresa. Todo ello con inmediatez y transparencia, utilizando un lenguaje cercano y ofreciendo contenidos relevantes. Así, sus principales funciones son las de conversar con la audiencia, escuchar y distribuir contenidos de la organización en los medios sociales (Castelló, 2010).

El Community Manager envía mensajes a través de plataformas como Facebook o Twitter, actualiza el estado de la empresa, revisa lo que se dice del producto, mercado y competencia, ofrece contenidos exclusivos (pre-estreno de campañas publicitarias en redes sociales, concursos y sorteos, etc.), revisa las estadísticas del perfil corporativo (tráfico de visitas, comentarios, participantes, etc.), monitoriza lo que se dice de la marca en la red e invita a los usuarios a interactuar con ella (Castelló, 2010).

Por todo ello, se consolida la importancia de la utilización de los blogs, y redes sociales tales como Facebook, Twitter, Google+, Pinterest y otras como complemento a los "websites específicos" para atraer la atención del navegante y a la vez utilizando herramientas 2.0 intentar conseguir la implicación del mismo, a través de comentarios, sugerencias o participando con el envío de contenidos. Se trata pues, de intentar actualizar y presentar casi diariamente nuevos contenidos referentes a las diversas zonas turísticas para que el visitante tenga una información continuamente renovada de los distintos lugares de España y animarle en su decisión de conocer y visitar los distintos destinos (Pombo, 2012).

\section{METODOLOGÍA}

Analizamos en este epígrafe el uso de las redes sociales por parte de las marcas turísticas de las distintas comunidades autónomas, incluidas además, las dos ciudades autónomas. 


\subsection{Muestra}

Para llevar a cabo el estudio se seleccionaron los diecisiete portales turísticos oficiales de las Comunidades Autónomas y además las dos Ciudades Autónomas, Ceuta y Melilla.

En la tabla 1 se muestran los nombres de las marcas turísticas destinadas a las campañas publicitarias en su página de marca en redes sociales, principalmente en Facebook, y en demás medios para dar a conocer a cada Comunidad Autónoma (CCAA) y las dos ciudades autónomas, así como sus webs de inicio.

Cabe mencionar, que las páginas de marca son un perfil público que representa y son utilizadas por empresas, organizaciones, marcas o personajes conocidos (Chu, 2011; Zaglia, 2013), que proporciona información a los usuarios y permite que éstos puedan responder a las comunicaciones realizadas por parte de la empresa; además las páginas de marca permiten a los usuarios publicar intereses, opiniones o cualquier otro tipo de información relacionada con la marca (Chatterjee, 2011).

Por tanto, una página de marca se puede considerar como un sitio web de una determinada marca dentro de la red social, en la que los consumidores pueden compartir su interés por la misma, intercambiar información o expresar sus preferencias (Zaglia, 2013).

Tabla 1

MARCAS TURÍSTICAS DE LAS CCAA Y LAS CIUDADES AUTÓNOMAS

\begin{tabular}{|l|l|l|}
\hline \multicolumn{1}{|c|}{ CCAA / Marca Turística } & Página de Marca en Facebook & \multicolumn{1}{c|}{ Enlace } \\
\hline Andalucía & Vive Andalucía & www.andalucia.org \\
\hline Islas Baleares & Illes Balears & www.illesbalears.es \\
\hline Canarias & Canary Islands & www.turismodecanarias.com \\
\hline Cataluña & Catalunya Experience & www.catalunya.com \\
\hline Comunidad Valenciana & Comunitat Valenciana & www.comunitatvalenciana.com \\
\hline Comunidad de Madrid & Turismo Madrid & www.turismomadrid.es \\
\hline Aragón & Turismo Aragón & www.turismodearagon.com \\
\hline Cantabria & Cantabria Infinita & www.turismodecantabria.com \\
\hline Castilla y León & Castilla y León es vida & www.turismocastillayleon.com \\
\hline Castilla-La Mancha & Turismo Castilla-La Mancha & www.turismocastillalamancha.com \\
\hline Comunidad Foral de Navarra & Turismo Reyno de Navarra & www.turismo.navarra.es \\
\hline Extremadura & Extremadura Turismo & www.turismoextremadura.com \\
\hline Galicia & Turgalicia & www.turgalicia.es \\
\hline La Rioja & La Rioja Turismo & www.lariojaturismo.com \\
\hline País Vasco & Visit Euskadi & www.turismoa.euskadi.net \\
\hline Principado de Asturias & Turismo Asturias & www.turismoasturias.es \\
\hline Región de Murcia & Destino Región de Murcia & www.murciaturistica.es \\
\hline \multicolumn{1}{|c|}{ Ciudad Autónoma } & & \\
\hline Ceuta & Turismo de Ceuta & www.destinoceuta.com \\
\hline Melilla & Melilla Turismo & www.melillaturismo.com \\
\hline
\end{tabular}

Fuente: elaboración propia. 


\subsection{Recogida de información}

Para obtener los datos necesarios, la recogida de la información se desarrolló en dos fases. En primer lugar se consultaron las páginas web de las diecisiete Comunidades Autónomas y las dos Ciudades Autónomas, identificando en cada una de ellas el logotipo o el nombre de las redes sociales en las que participaba.

Posteriormente, se consultó para cada una de las marcas su participación y actividad en redes sociales. Esta fase incluyó:

1) la búsqueda directa de las marcas a través de cada una de las principales redes sociales, para identificar si tenían presencia o no en las mismas,

2) las características de cada una de las páginas de marca en la red social Facebook, por ser ésta la red social más utilizada y

3) la actividad que cada una de las marcas establece con el usuario a través de la red social Facebook.

Respecto a la actividad de las marcas en Facebook, para su análisis se utilizó el modelo PRGS, propuesto por IAB Spain Research para llevar a cabo el "Estudio Actividad de las marcas en medios sociales" de los años 2012, 2013 y 2015. El modelo PRGS se basa en 4 variables (Presencia, Respuesta, Generación y Sugerencia) para medir la actividad de las marcas en redes sociales. En el ámbito de la red social Facebook, dichas variables se miden según se indica a continuación.

\section{Tabla 2 \\ MODELO PRGS}

\begin{abstract}
Presencia: Su medida se relaciona con la actividad de la marca y viene dada por el número de fans o seguidores y el número de publicaciones que la marca realiza en la página.
\end{abstract}

Generación: Su medida se relaciona con la actividad del usuario y viene dada por el número de comentarios que los mismos generan ante las publicaciones de la marca.
Respuesta: $\mathrm{Su}$ medida se relaciona con la actividad del usuario y viene dada por el número de me gusta que los mismos generan ante las publicaciones de la marca.

Sugerencia: Su medida se relaciona con la actividad del usuario y viene dada por el número de comparticiones que los mismos generan ante las publicaciones de la marca.

Fuente: elaboración propia a partir del documento II Estudio Actividad de las marcas en medios sociales, iabSpain 2013.

La tabla 3 muestra el cálculo que debe realizarse y los valores necesarios para calcular cada una de las variables en las que se basa el modelo. 
Tabla 3

VARIABLES DEL MODELO PRGS ANALIZADAS

EN LA RED SOCIAL FACEBOOK

\begin{tabular}{|l|l|l|l|}
\hline \multirow{2}{*}{ MARCA } & \multirow{2}{*}{ Presencia } & Fans & \multirow{2}{*}{$\mathrm{P}=\mathrm{n}^{\mathrm{o}}$ post } \\
\cline { 3 - 4 } & & Post & \\
\hline \multirow{3}{*}{ USUARIO } & Respuesta & Me Gusta & $\mathrm{R}=\mathrm{Me}$ Gusta $/ \mathrm{n}^{\circ}$ fans \\
\cline { 2 - 4 } & Generación & Comentarios & $\mathrm{G}=$ Comentarios $/ \mathrm{n}^{\circ}$ fans \\
\cline { 2 - 4 } & Sugerencia & Contenido compartido & $\mathrm{S}=$ Compartir $/ \mathrm{n}^{\circ}$ fans \\
& & & \\
\hline
\end{tabular}

Fuente: elaboración propia a partir del documento II Estudio Actividad de las marcas en medios sociales, iabSpain 2013.

La variable Presencia se mide en valor absoluto, ya que consideramos que la actividad que realice la marca en su página será independientemente del número de fans que posea. Por el contrario, las variables Respuesta, Generación y Sugerencia se miden en valor relativo, en función del número de fans de la página, ya que la actividad que el usuario realice en la página dependerá o estará condicionada por dicho número (Giraldo y Sánchez, 2015; Giraldo y Martínez, 2015).

La recogida de la información se realizó de forma manual, almacenando los datos mensualmente desde enero de 2014 a marzo de 2015, siendo de gran ayuda la herramienta Smétrica para el registro de la información referente a la actividad de las marcas en Facebook (número de fans, número de publicaciones, número de comentarios, número de me gusta, número de comparticiones).

Además, para cada una de las variables se calculó el valor medio, permitiendo identificar las marcas de las Comunidades Autónomas que superan o no el mismo, y se creó un gráfico para cada una de dichas variables, en las que se incluyeron los resultados de todos y cada uno de los meses analizados.

\section{RESULTADOS}

Se exponen aquí los principales resultados del estudio estructurados en dos partes; en primer lugar se realiza un análisis descriptivo en el que se refleja una perspectiva global de la participación de las marcas en las principales redes sociales y en segundo lugar se analiza el modelo PRGS en Facebook.

\subsection{Análisis Descriptivo}

Tras la primera fase de recogida de la información, se identificó que el total de marcas turísticas de las Comunidades Autónomas tienen logo o enlace a, al menos, una red social. En relación a la segunda fase, relacionada con la participación y actividad en redes 
sociales, tras acceder a cada una de las principales redes sociales se identificó que todas las Comunidades Autónomas, incluidas también las dos Ciudades Autónomas, participan en redes sociales.

Así, Facebook y Twitter son las redes sociales por excelencia participadas por el $100 \%$ de las marcas turísticas. También se ha comprobado la presencia en redes sociales como YouTube, Pinterest e Instagram.

Para llevar a cabo el estudio se analizó concretamente la actividad en Facebook ya que es la red social más utilizada en el sector turístico, y comprobamos que las marcas turísticas ofrecen a los usuarios, que a su vez son turistas potenciales, además de información, biografía y fotos, las cuales vienen incluidas por defecto la página de la red social, otras características como eventos, vídeos, rutas gastronómicas, publicaciones externas y enlaces a otras redes sociales en las que tienen presencia.

\subsection{Análisis del Modelo PRGS en Facebook}

Como se ha mencionado, el análisis de la actividad de las marcas en Facebook se realizó a partir del modelo PRGS. En el momento de llevar a cabo el análisis, de las 17 marcas turísticas de las Comunidades Autónomas (CCAA) y las 2 Ciudades Autónomas con presencia en Facebook, 10 CCAA y Melilla se encontraban en seguimiento por la herramienta Smétrica, es decir, existían datos disponibles sobre la actividad de 11 marcas turísticas, de un total de 19, por tanto son éstas las analizadas. En la tabla 4 se muestra un listado de dichas marcas.

Tabla 4

MARCAS TURÍSTICAS DE LAS CCAA EN SEGUIMIENTO POR SMÉTRICA

\begin{tabular}{|l|l|l|}
\hline \multicolumn{1}{|c|}{ CCAA / Marca } & \multicolumn{1}{c|}{$\begin{array}{c}\text { Página de Marca en } \\
\text { Facebook }\end{array}$} & \multicolumn{1}{c|}{ Enlace } \\
\hline Andalucía & Vive Andalucía & www.andalucia.org \\
\hline Canarias & Canary Islands & www.turismodecanarias.com \\
\hline Cataluña & Catalunya Experience & www.catalunya.com \\
\hline Comunidad Valenciana & Comunitat Valenciana & www.comunitatvalenciana.com \\
\hline Comunidad de Madrid & Turismo Madrid & www.turismomadrid.es \\
\hline Cantabria & Cantabria Infinita & www.turismodecantabria.com \\
\hline Castilla y León & Castilla y León es vida & www.turismocastillayleon.com \\
\hline Castilla-La Mancha & Turismo Castilla-La Mancha & www.turismocastillalamancha.com \\
\hline Galicia & Turgalicia & www.turgalicia.es \\
\hline Principado de Asturias & Turismo Asturias & www.turismoasturias.es \\
\hline \multicolumn{1}{|c|}{ Ciudad Autónoma } & & \\
\hline Melilla & Melilla Turismo & www.melillaturismo.com \\
\hline
\end{tabular}

Fuente: elaboración propia. 
Los resultados obtenidos para cada uno de los meses analizados se describen a continuación.

\subsubsection{Presencia}

Tal y como se refleja en el gráfico 1, las marcas turísticas de las Comunidades Autónomas que tienen mayor nivel de Presencia en Facebook, durante el período analizado son la Comunidad Valenciana, seguida de Cataluña y Canarias que registra su mayor número de publicaciones en los meses comprendidos desde julio hasta septiembre. Dicho comportamiento es similar a lo largo de los 15 meses estudiados.

\section{Gráfico 1 \\ PRESENCIA DE LAS 11 MARCAS TURÍSTICAS \\ ENTRE ENERO DE 2014 Y MARZO DE 2015}

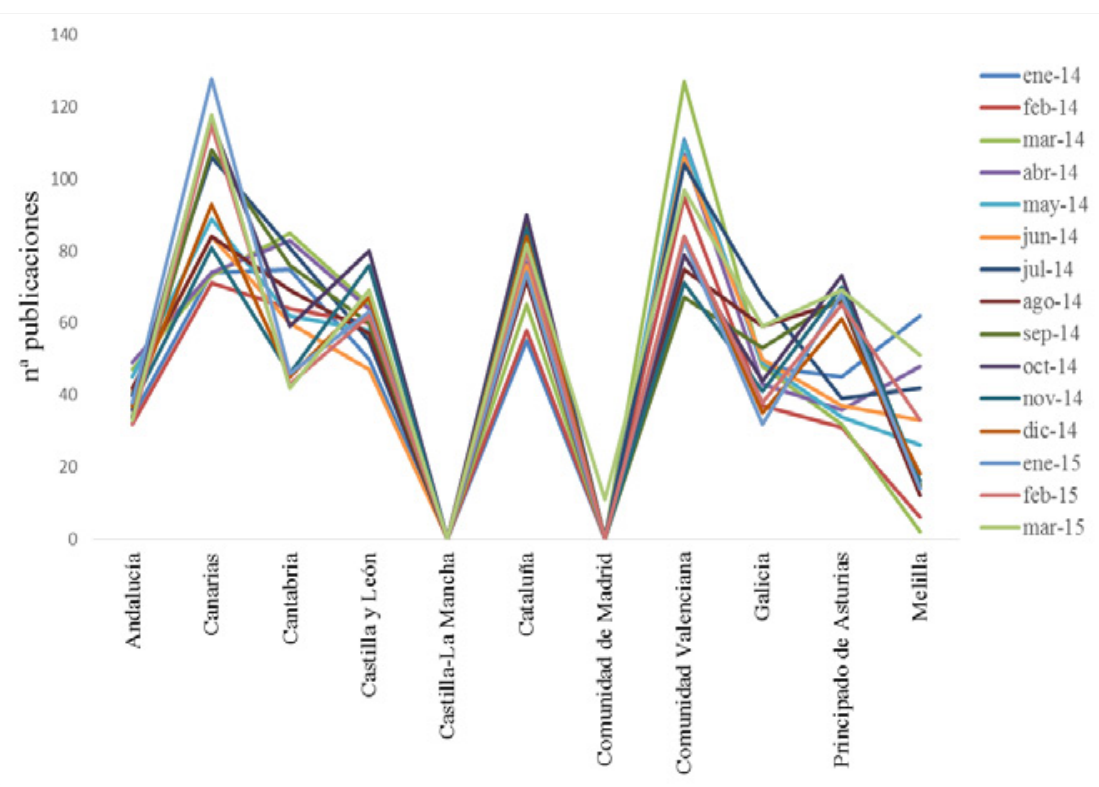

Fuente: elaboración propia.

Los resultados anteriores se reflejan en la tabla 5, en la que además se incluye la media calculada para cada uno de los meses analizados.

Respecto a la presencia medida en términos de fans, Cataluña, con un total de 489.389 fans, se sitúa como la marca turística que tiene la mayor comunidad en Facebook entre las Comunidades y Ciudades autónomas analizadas, seguida de la Comunidad Valenciana (90.509) y Principado de Asturias (88.726). 
Tabla 5

PRESENCIA DE LAS 11 MARCAS TURÍSTICAS

ENTRE ENERO DE 2014 Y MARZO DE 2015

\begin{tabular}{|c|c|c|c|c|c|c|c|c|}
\hline CCAA & ene-14 & feb-14 & mar-14 & abr-14 & may-14 & jun-14 & jul- 14 & ago-14 \\
\hline Media & 50 & 41 & 49 & 53 & 50 & 49 & 56 & 49 \\
\hline Andalucía & 34 & 32 & 47 & 49 & 45 & 41 & 40 & 42 \\
\hline Canarias & 74 & 71 & 73 & 74 & 89 & 84 & 106 & 84 \\
\hline Cantabria & 75 & 64 & 85 & 83 & 62 & 60 & 81 & 69 \\
\hline Castilla y León & 50 & 60 & 65 & 64 & 58 & 47 & 55 & 57 \\
\hline Castilla-La Mancha & 0 & 0 & 0 & 0 & 0 & 0 & 0 & 0 \\
\hline Cataluña & 55 & 58 & 65 & 77 & 80 & 76 & 82 & 72 \\
\hline Comunidad de Madrid & 0 & 0 & 0 & 0 & 0 & 0 & 0 & 0 \\
\hline Comunidad Valenciana & 111 & 95 & 127 & 107 & 110 & 106 & 104 & 75 \\
\hline Galicia & 48 & 37 & 48 & 43 & 49 & 50 & 67 & 59 \\
\hline Principado de Asturias & 45 & 31 & 32 & 36 & 34 & 37 & 39 & 66 \\
\hline \multicolumn{9}{|l|}{ Ciudad Autónoma } \\
\hline Melilla & 62 & 6 & 2 & 48 & 26 & 33 & 42 & 12 \\
\hline CCAA & sep-14 & oct-14 & nov-14 & dic-14 & ene-15 & feb-15 & mar-15 & \\
\hline Media & 52 & 54 & 48 & 48 & 50 & 50 & 57 & \\
\hline Andalucía & 34 & 36 & 37 & 37 & 38 & 32 & 33 & \\
\hline Canarias & 108 & 116 & 81 & 93 & 128 & 115 & 118 & \\
\hline Cantabria & 76 & 59 & 46 & 45 & 46 & 43 & 42 & \\
\hline Castilla y León & 60 & 80 & 76 & 67 & 63 & 62 & 69 & \\
\hline Castilla-La Mancha & 0 & 0 & 0 & 0 & 0 & 0 & 0 & \\
\hline Cataluña & 88 & 90 & 86 & 84 & 74 & 80 & 82 & \\
\hline Comunidad de Madrid & 0 & 0 & 0 & 0 & 0 & 0 & 11 & \\
\hline Comunidad Valenciana & 67 & 79 & 71 & 84 & 83 & 84 & 97 & \\
\hline Galicia & 53 & 44 & 41 & 35 & 32 & 38 & 59 & \\
\hline Principado de Asturias & 67 & 73 & 70 & 61 & 68 & 65 & 69 & \\
\hline \multicolumn{9}{|l|}{ Ciudad Autónoma } \\
\hline Melilla & 15 & 14 & 16 & 18 & 14 & 33 & 51 & \\
\hline
\end{tabular}

Fuente: elaboración propia. Los datos señalados en color azul indican las principales Marcas Turísticas de las Comunidades Autónomas que destacan por encima de la media calculada para el periodo analizado. 


\subsubsection{Respuesta}

Tal y como se refleja en el gráfico 2, la marca turística de la Comunidad Autónoma de Cantabria es la que mayor respuesta genera de entre todas las marcas de las Comunidades y Ciudades Autónomas estudiadas, siendo líder a lo largo de los 15 meses analizados, con más de un $60 \%$ de respuesta mensual en el sector, superando incluso, el $100 \%$ en algunos meses. Las siguientes marcas turísticas son Canarias, la Comunidad Valenciana y Principado de Asturias.

El resto de marcas que destacan en el análisis de esta variable durante todo este período de tiempo son Castilla y León y Cataluña, cuya tasa de respuesta mensual está por encima de la media calculada para cada una de las marcas turísticas.

\section{Gráfico 2 \\ TASA DE RESPUESTA DE LAS 11 MARCAS TURÍSTICAS \\ ENTRE ENERO DE 2014 Y MARZO DE 2015}

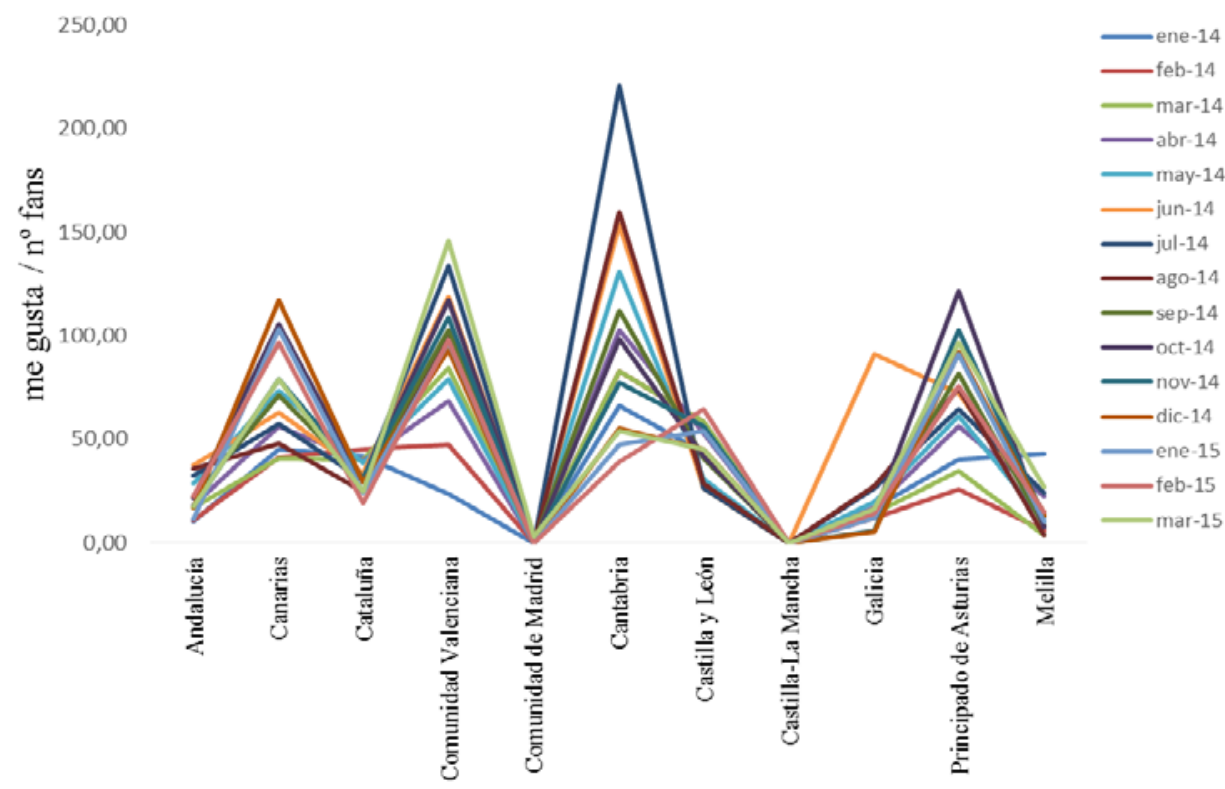

Fuente: elaboración propia.

Los resultados anteriores se reflejan en la tabla 6 . 


\section{Tabla 6}

\section{TASA DE RESPUESTA DE LAS 11 MARCAS TURÍSTICAS ENTRE ENERO DE 2014 Y MARZO DE 2015}

\begin{tabular}{|c|c|c|c|c|c|c|c|c|}
\hline CCAA & ene-14 & feb-14 & mar-14 & abr-14 & may-14 & jun-14 & jul-14 & ago-14 \\
\hline Media & 29,99 & 29,91 & 34,15 & 39,32 & 42,94 & 55,49 & 55,90 & 45,87 \\
\hline Andalucía & 10,08 & 11,02 & 16,85 & 18,11 & 28,30 & 37,24 & 32,29 & 35,67 \\
\hline Canarias & 45,01 & 41,02 & 40,87 & 56,18 & 73,10 & 62,99 & 57,06 & 48,10 \\
\hline Cataluña & 41,83 & 45,15 & 39,95 & 39,48 & 38,67 & 33,40 & 30,19 & 24,91 \\
\hline Comunidad Valenciana & 23,71 & 47,36 & 84,64 & 68,23 & 79,10 & 118,85 & 133,69 & 102,20 \\
\hline Comunidad de Madrid & 0,00 & 0,00 & 0,00 & 0,00 & 0,00 & 0,00 & 0,00 & 0,00 \\
\hline Cantabria & 65,88 & 82,71 & 82,46 & 102,74 & 130,98 & 153,47 & 220,62 & 159,51 \\
\hline Castilla y León & 43,59 & 58,50 & 58,49 & 52,59 & 30,86 & 26,59 & 26,15 & 28,75 \\
\hline Castilla-La Mancha & 0,00 & 0,00 & 0,00 & 0,00 & 0,00 & 0,00 & 0,00 & 0,00 \\
\hline Galicia & 16,92 & 11,85 & 14,34 & 16,68 & 19,77 & 90,89 & 26,39 & 27,18 \\
\hline Principado de Asturias & 40,12 & 25,57 & 34,34 & 56,16 & 61,30 & 72,07 & 64,52 & 74,35 \\
\hline \multicolumn{9}{|l|}{ Ciudad Autónoma } \\
\hline Melilla & 42,70 & 5,85 & 3,73 & 22,41 & 10,30 & 14,88 & 24,03 & 3,91 \\
\hline CCAA & sep-14 & oct-14 & nov-14 & dic-14 & ene-15 & feb-15 & mar-15 & \\
\hline Media & 43,86 & 50,55 & 44,63 & 42,41 & 40,88 & 40,31 & 46,23 & \\
\hline Andalucía & 22,13 & 21,53 & 17,58 & 17,05 & 11,32 & 22,23 & 17,44 & \\
\hline Canarias & 71,20 & 105,35 & 78,98 & 117,07 & 103,29 & 96,80 & 79,07 & \\
\hline Cataluña & 30,46 & 29,45 & 31,14 & 28,83 & 23,85 & 18,89 & 24,45 & \\
\hline Comunidad Valenciana & 102,68 & 117,11 & 108,79 & 93,44 & 97,32 & 97,57 & 145,63 & \\
\hline Comunidad de Madrid & 0,00 & 0,00 & 0,00 & 0,00 & 0,00 & 0,00 & 2,83 & \\
\hline Cantabria & 112,01 & 98,37 & 77,42 & 54,87 & 47,34 & 38,89 & 53,82 & \\
\hline Castilla y León & 40,90 & 41,74 & 56,19 & 45,03 & 53,92 & 64,62 & 45,18 & \\
\hline Castilla-La Mancha & 0,00 & 0,00 & 0,00 & 0,00 & 0,00 & 0,00 & 0,00 & \\
\hline Galicia & 13,07 & 13,38 & 5,84 & 5,35 & 11,72 & 14,04 & 16,46 & \\
\hline Principado de Asturias & 81,82 & 121,68 & 102,46 & 91,94 & 90,83 & 75,54 & 96,55 & \\
\hline Melilla & 8,24 & 7,46 & 12,51 & 12,97 & 10,13 & 14,78 & 27,05 & \\
\hline
\end{tabular}

Fuente: elaboración propia. Valores expresados en porcentaje. Los datos señalados en color azul indican las principales Marcas Turísticas de las Comunidades Autónomas que destacan por encima de la media calculada para el periodo analizado. 


\subsubsection{Generación}

En el gráfico 3 se muestran los resultados en cuanto a la generación de comentarios de manera proactiva por parte del usuario en los perfiles de las marcas turísticas de las Comunidades y Ciudades Autónomas analizadas. La Comunidad Valenciana, Cantabria y Canarias lideran el ranking durante los 15 meses estudiados. Las marcas turísticas de dichas CCAA han mantenido una actividad constante de generación de contenidos. A continuación, se encuentran Castilla y León y Principado de Asturias, donde el usuario ha participado activamente comentando las publicaciones realizadas por las marcas.

\section{Gráfico 3 \\ TASA DE GENERACIÓN DE CONTENIDO \\ DE LAS 11 MARCAS TURÍSTICAS \\ ENTRE ENERO DE 2014 Y MARZO DE 2015}

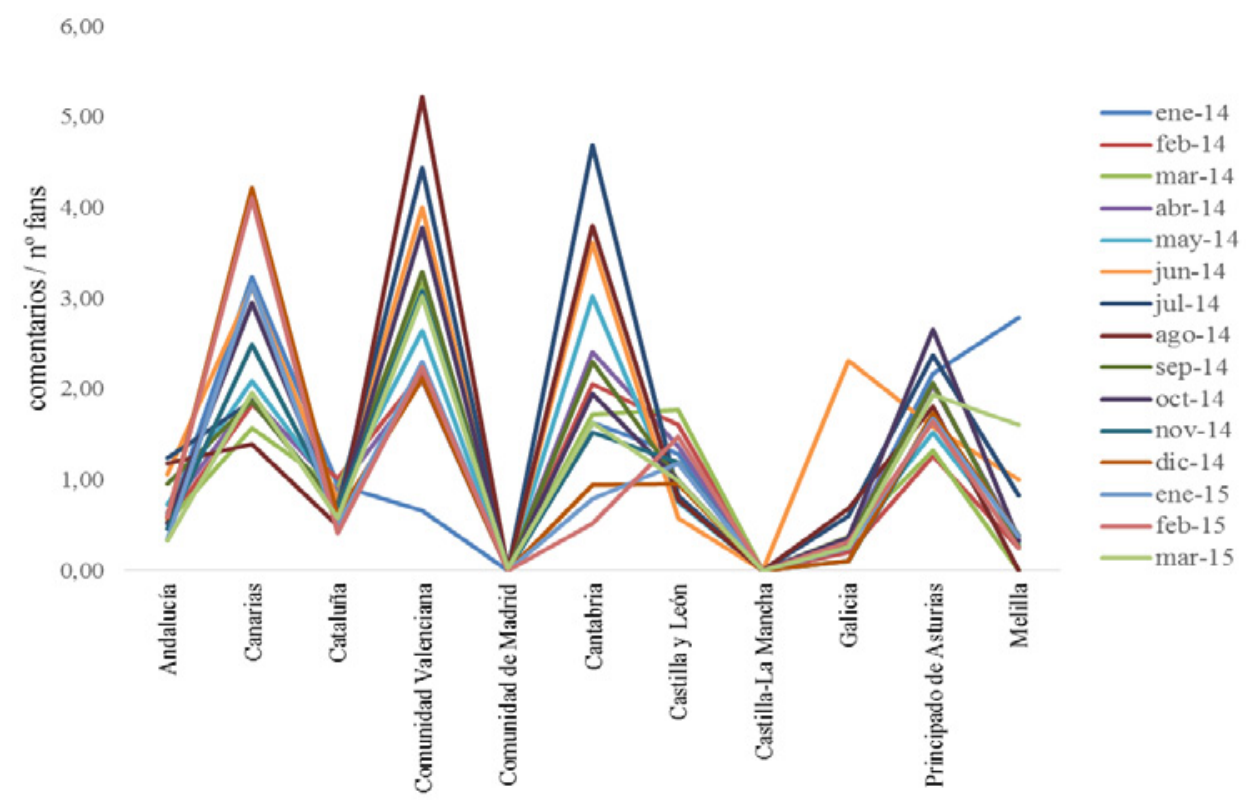

Fuente: elaboración propia.

Los resultados anteriores se reflejan de forma detallada en la tabla 7. 
Tabla 7

TASA DE GENERACIÓN DE CONTENIDO DE LAS 11 MARCAS TURÍSTICAS ENTRE ENERO DE 2014 Y MARZO DE 2015

\begin{tabular}{|c|c|c|c|c|c|c|c|c|}
\hline CCAA & ene-14 & feb-14 & mar-14 & abr-14 & may-14 & jun-14 & jul-14 & ago-14 \\
\hline Media & 1,23 & 0,99 & 1,03 & 1,09 & 1,11 & 1,64 & 1,60 & 1,40 \\
\hline Andalucía & 0,52 & 0,53 & 0,53 & 0,63 & 0,74 & 1,06 & 1,23 & 1,18 \\
\hline Canarias & 3,23 & 1,83 & 1,57 & 1,91 & 2,09 & 3,12 & 1,86 & 1,39 \\
\hline Cataluña & 0,94 & 1,01 & 0,89 & 0,87 & 0,83 & 0,76 & 0,71 & 0,50 \\
\hline Comunidad Valenciana & 0,66 & 2,18 & 3,16 & 2,09 & 2,64 & 4,00 & 4,44 & 5,22 \\
\hline Comunidad de Madrid & 0,00 & 0,00 & 0,00 & 0,00 & 0,00 & 0,00 & 0,00 & 0,00 \\
\hline Cantabria & 1,63 & 2,05 & 1,72 & 2,41 & 3,02 & 3,61 & 4,68 & 3,80 \\
\hline Castilla y León & 1,28 & 1,61 & 1,76 & 1,36 & 0,75 & 0,58 & 0,83 & 0,78 \\
\hline Castilla-La Mancha & 0,00 & 0,00 & 0,00 & 0,00 & 0,00 & 0,00 & 0,00 & 0,00 \\
\hline Galicia & 0,34 & 0,20 & 0,38 & 0,36 & 0,34 & 2,32 & 0,60 & 0,68 \\
\hline Principado de Asturias & 2,17 & 1,27 & 1,33 & 2,05 & 1,52 & 1,58 & 2,37 & 1,80 \\
\hline \multicolumn{9}{|l|}{ Ciudad Autónoma } \\
\hline Melilla & 2,78 & 0,25 & 0,00 & 0,32 & 0,30 & 1,00 & 0,83 & 0,00 \\
\hline CCAA & sep-14 & oct-14 & nov-14 & dic-14 & ene-15 & feb-15 & mar-15 & \\
\hline Media & 1,16 & 1,29 & 1,05 & 1,06 & 0,96 & 1,05 & 1,12 & \\
\hline Andalucía & 0,95 & 0,52 & 0,46 & 0,58 & 0,34 & 0,59 & 0,33 & \\
\hline Canarias & 1,86 & 2,96 & 2,49 & 4,22 & 3,15 & 4,11 & 1,96 & \\
\hline Cataluña & 0,69 & 0,64 & 0,67 & 0,60 & 0,48 & 0,41 & 0,57 & \\
\hline Comunidad Valenciana & 3,30 & 3,77 & 3,08 & 2,11 & 2,30 & 2,24 & 3,02 & \\
\hline Comunidad de Madrid & 0,00 & 0,00 & 0,00 & 0,00 & 0,00 & 0,00 & 0,02 & \\
\hline Cantabria & 2,30 & 1,94 & 1,52 & 0,95 & 0,79 & 0,51 & 1,63 & \\
\hline Castilla y León & 1,00 & 0,99 & 1,19 & 0,95 & 1,18 & 1,47 & 0,99 & \\
\hline Castilla-La Mancha & 0,00 & 0,00 & 0,00 & 0,00 & 0,00 & 0,00 & 0,00 & \\
\hline Galicia & 0,30 & 0,36 & 0,10 & 0,10 & 0,25 & 0,32 & 0,26 & \\
\hline Principado de Asturias & 2,07 & 2,65 & 1,69 & 1,73 & 1,67 & 1,64 & 1,94 & \\
\hline \multicolumn{9}{|l|}{ Ciudad Autónoma } \\
\hline Melilla & 0,27 & 0,33 & 0,38 & 0,38 & 0,37 & 0,24 & 1,60 & \\
\hline
\end{tabular}

Fuente: elaboración propia. Los datos señalados en color azul indican las principales Marcas Turísticas de las Comunidades Autónomas que destacan por encima de la media calculada para el periodo analizado. 


\subsubsection{Sugerencia}

En el gráfico 4 se muestra el contenido de la marca turística que los usuarios deciden publicar en sus propios perfiles, a través de recomendaciones o la compartición de contenido. En este período de tiempo, lidera el ranking la marca de la Comunidad Valenciana. A continuación se encuentran Cantabria y Principado de Asturias y en las siguientes posiciones, destacan también Canarias y Castilla y León. Este comportamiento es similar a lo largo del período analizado.

\section{Gráfico 4 \\ TASA DE SUGERENCIA DE LAS 11 MARCAS TURÍSTICAS ENTRE ENERO DE 2014 Y MARZO DE 2015}

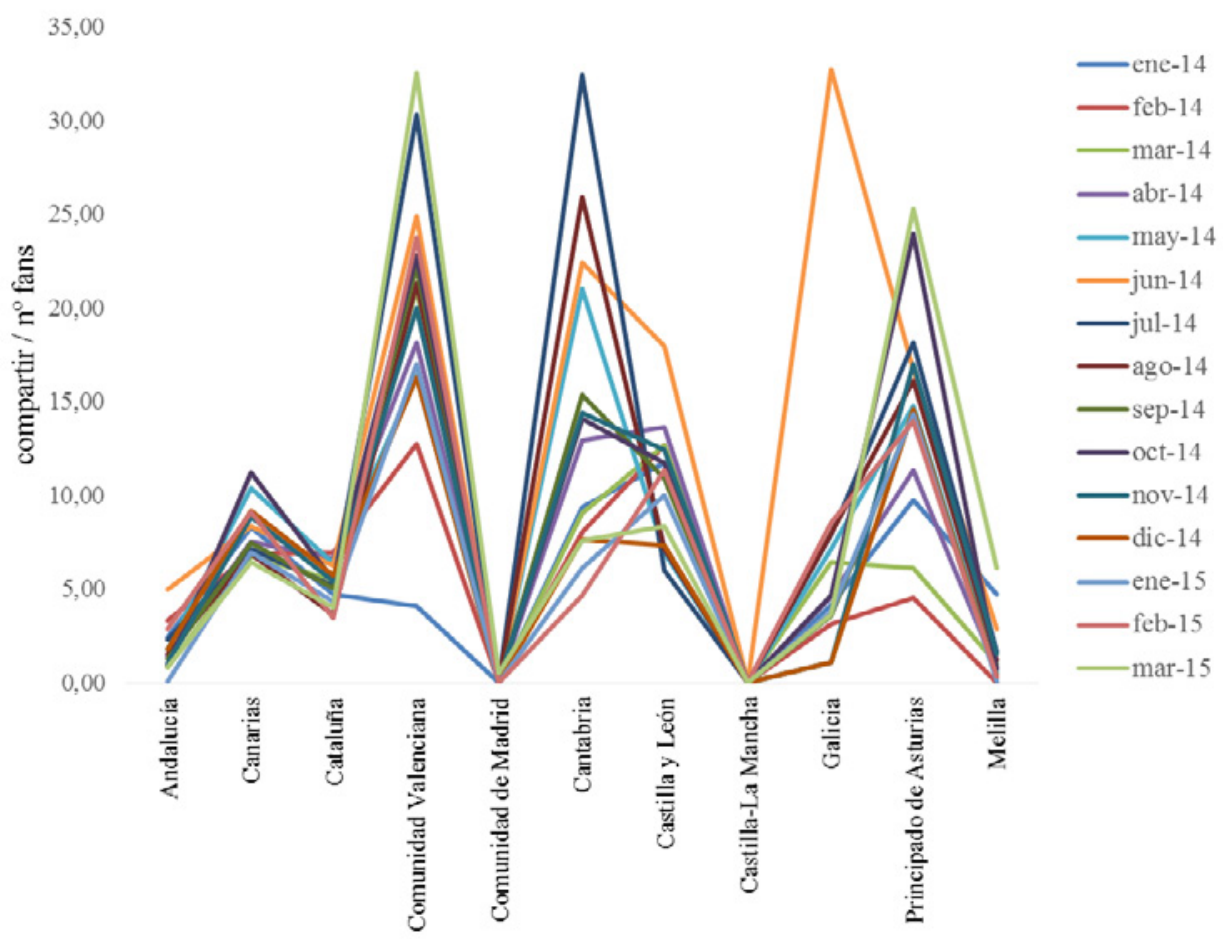

Fuente: elaboración propia.

Los resultados anteriores se reflejan en la tabla 8 . 
Tabla 8

TASA DE SUGERENCIA DE LAS 11 MARCAS TURÍSTICAS ENTRE ENERO DE 2014 Y MARZO DE 2015

\begin{tabular}{|c|c|c|c|c|c|c|c|c|}
\hline CCAA & ene-14 & feb-14 & mar-14 & abr-14 & may-14 & jun-14 & jul-14 & ago-14 \\
\hline Media & 5,39 & 5,29 & 6,32 & 6,99 & 7,76 & 12,46 & 10,09 & 8,34 \\
\hline Andalucía & 2,45 & 3,30 & 0,86 & 1,41 & 1,80 & 4,94 & 2,30 & 1,52 \\
\hline Canarias & 8,28 & 6,90 & 6,75 & 7,53 & 10,36 & 8,38 & 7,14 & 6,91 \\
\hline Cataluña & 4,71 & 6,94 & 5,49 & 6,65 & 6,35 & 6,26 & 5,15 & 3,64 \\
\hline Comunidad Valenciana & 4,09 & 12,71 & 21,03 & 18,14 & 16,36 & 24,87 & 30,33 & 21,31 \\
\hline Comunidad de Madrid & 0,00 & 0,00 & 0,00 & 0,00 & 0,00 & 0,00 & 0,00 & 0,00 \\
\hline Cantabria & 9,37 & 8,01 & 9,07 & 12,90 & 21,03 & 22,38 & 32,39 & 25,91 \\
\hline Castilla y León & 11,72 & 12,65 & 12,68 & 13,66 & 6,97 & 17,95 & 5,98 & 7,14 \\
\hline Castilla-La Mancha & 0,00 & 0,00 & 0,00 & 0,00 & 0,00 & 0,00 & 0,00 & 0,00 \\
\hline Galicia & 4,17 & 3,11 & 6,43 & 4,60 & 7,13 & 32,75 & 7,92 & 7,96 \\
\hline Principado de Asturias & 9,75 & 4,55 & 6,13 & 11,35 & 14,75 & 16,69 & 18,15 & 16,11 \\
\hline \multicolumn{9}{|l|}{ Ciudad Autónoma } \\
\hline Melilla & 4,70 & 0,00 & 1,06 & 0,63 & 0,60 & 2,86 & 1,66 & 1,21 \\
\hline CCAA & sep-14 & oct-14 & nov-14 & dic-14 & ene-15 & feb-15 & mar-15 & \\
\hline Media & 7,32 & 8,69 & 7,43 & 5,81 & 5,69 & 7,09 & 8,66 & \\
\hline Andalucía & 1,25 & 0,91 & 1,01 & 1,79 & 0,09 & 2,86 & 0,82 & \\
\hline Canarias & 7,45 & 11,19 & 8,83 & 9,15 & 6,93 & 9,12 & 6,41 & \\
\hline Cataluña & 5,02 & 5,47 & 5,43 & 5,71 & 4,31 & 3,48 & 4,03 & \\
\hline Comunidad Valenciana & 22,20 & 22,79 & 19,99 & 16,33 & 16,98 & 23,72 & 32,54 & \\
\hline Comunidad de Madrid & 0,00 & 0,00 & 0,00 & 0,00 & 0,00 & 0,00 & 0,52 & \\
\hline Cantabria & 15,34 & 14,10 & 14,39 & 7,67 & 6,10 & 4,66 & 7,61 & \\
\hline Castilla y León & 10,89 & 11,75 & 12,42 & 7,33 & 10,02 & 11,35 & 8,34 & \\
\hline Castilla-La Mancha & 0,00 & 0,00 & 0,00 & 0,00 & 0,00 & 0,00 & 0,00 & \\
\hline Galicia & 3,58 & 4,63 & 1,06 & 1,11 & 3,77 & 8,57 & 3,61 & \\
\hline Principado de Asturias & 14,41 & 23,96 & 17,01 & 14,61 & 14,32 & 13,93 & 25,26 & \\
\hline \multicolumn{9}{|l|}{ Ciudad Autónoma } \\
\hline Melilla & 0,40 & 0,79 & 1,54 & 0,25 & 0,06 & 0,30 & 6,11 & \\
\hline
\end{tabular}

Fuente: elaboración propia. Los datos señalados en color azul indican las principales Marcas Turísticas de las Comunidades Autónomas que destacan por encima de la media calculada para el periodo analizado. 


\section{CONCLUSIONES}

Teniendo en cuenta el elevado crecimiento de usuarios de redes sociales durante los últimos años y su consideración como clientes potenciales para las empresas, sobre todo en el sector turístico, se ha pretendido analizar el uso de las redes sociales para establecer relaciones con los clientes de los portales que recogen las denominadas marcas turísticas. A continuación se exponen los principales datos y conclusiones extraídos del estudio.

Del total de marcas analizadas que componen los portales turísticos de las Comunidades Autónomas y las Ciudades Autónomas, un 100\% participan en redes sociales. Estos datos indican que el uso de redes sociales por parte de este tipo de los Portales Turísticos es una realidad y sugieren, además, que las CCAA apuestan por el uso de redes sociales como parte de su estrategia de promoción turística y comercial.

Facebook y Twitter son las dos redes sociales por excelencia y alcanzan un nivel de presencia del $100 \%$ sobre el total de la muestra analizada.

Aunque en este estudio, la variable Presencia se midió en valor absoluto, ya que se considera que la actividad que realice la marca turística en su perfil será independiente del número de fans que posea, en este caso, queda reflejado que las Comunidades Autónomas con mayor actividad en la red social Facebook a lo largo de todo el período analizado han sido la Comunidad Valenciana, Cataluña y Canarias, lo que coincide con el nivel de Presencia medido en términos de fans y podría implicar que a mayor volumen de seguidores, mayor cantidad de interacciones con el usuario y la marca (me gusta, comentarios y compartir), y por consiguiente mayor posibilidad de obtener nuevos seguidores que podrían convertirse en turistas potenciales.

Sorprendentemente se ha detectado un error en la recolección de datos utilizando la herramienta Smétrica, ya que aunque tiene en seguimiento las marcas turísticas de Madrid y de Castilla-La Mancha, no tiene almacenados los datos para poder calcular las variables del modelo PRGS, lo que induce a pensar que ambas marcas turísticas tienen perfil en la red social, pero que no participan en ella. Una vez visitado el perfil de ambas, se detecta actividad e interacción de ambas marcas con el usuario, lo que confirma el error de almacenamiento de datos con dicha herramienta, pero al disponer del número de fans mensuales, necesario para calcular cada una de las variables que componen el modelo, se pudo realizar de forma manual y obtener así la información para incorporarla finalmente en el estudio.

En este estudio, se ha pretendido analizar la actividad que las marcas turísticas de las Comunidades Autónomas Españolas llevan a cabo en la red social Facebook a través del modelo PRGS. Así, destacan Comunidad Valenciana y Cantabria y Canarias como aquellas marcas turísticas que presentan mayor actividad durante todo el periodo analizado. Estas marcas turísticas proponen una serie de opciones para que el turista pueda conocer y disfrutar de los recursos de dichas comunidades como visitas guiadas por las distintas ciudades, ofertas para conocer el patrimonio histórico y cultural, paisajes, playas, ferias, escapadas gastronómicas, fiestas de interés turístico nacional y concursos cuyo premio consiste en entradas a conciertos, festivales o parques temáticos, entre otros.

Con todas estas acciones, comprobamos que las marcas turísticas y cadenas hoteleras consiguen aumentar su nivel de actividad en la red social y fomentan la participación y el interés de los usuarios, ya que al mostrar en los medios sociales los atractivos de los 
destinos, hoteles y entorno, no sólo permite fidelizar a los clientes existentes sino que es una buena forma de atraer nuevos clientes y ofrecerles la mejor experiencia posible.

Los resultados reflejan que el éxito de las marcas turísticas en las redes sociales medido a través de la participación del usuario, no sólo depende del número de seguidores. Es decir, que la marca tenga un mayor número de usuarios activos no se debe necesariamente a que tenga mayor número de seguidores, sino que puede depender en gran medida del contenido que se genere por parte de la propia marca, el tipo y la calidad del contenido publicado es importante, ya podría influir en la decisión de compra de aquellos turistas potenciales que estén planificando sus vacaciones y se les ofrezca una variada y atractiva información de la oferta turística global de España y a la vez específica de cada destino.

Limitaciones metodológicas y posibles líneas de investigación futuras:

La elaboración de este trabajo no ha estado exenta de dificultades. Pese a la utilidad de la herramienta Smétrica, ésta no tenía datos de la actividad de algunas marcas turísticas. Por este motivo se procedió a recogerlos de forma manual desde la página de la marca en Facebook, lo que puede ser un inconveniente si se recolectan datos de una muestra grande ya que hay que revisar cada una de las publicaciones diarias que realiza la marca en la red social y esto implica una inversión importante de tiempo y además, la probabilidad de cometer errores en el almacenamiento de los datos. Finalmente hubo que descartar algunas de ellas por no disponer del número de fans mensuales, dato necesario para poder calcular las variables del modelo PRGS.

Por otro lado señalar que en el momento de la recolección de los datos se pusieron en seguimiento todas a aquellas marcas de las que no disponía datos la herramienta Smétrica, por lo que en un horizonte temporal próximo, estarán disponibles y sería posible analizar la actividad del conjunto de las marcas turísticas de las Comunidades Autónomas.

Para finalizar y como futura línea de investigación, se podría aplicar el modelo PRGS a otra red social como Twitter y analizar la actividad que las marcas realizan en ella, y así sería posible comparar la actividad en ambas RRSS y poder realizar un análisis más profundo del comportamiento de las variables estudiadas en el modelo.

\section{BIBLIOGRAFÍA}

ALVARADO, P. (2012): «Impacto de las redes sociales sobre las variables de decisiones de los agentes». Unidad de Informática y Comunicaciones de la Facultad de Ciencias Económicas de la Universidad Nacional de Colombia, pp. 1-30.

ANDEMA (2001): «¿Qué son las marcas?». Asociación Nacional para la defensa de la Marca, página web: http://andema.camaras.org

BEERLI, A., y MARTÍN, J.D. (2002): «El proceso de formación de la imagen de los destinos turísticos: una revisión teórica». Estudios Turísticos, 154, pp. 5-32.

BEERLI, A., y MARTÍN, J.D. (2004): «Tourists characteristic and the perceived image of tourist destinations: a quantitative analysis - A case study of Lanzarote, Spain». Tourism Management, 25, pp. 623-636.

BIGNÉ, J. et al., (2001): «Tourism image, evaluation variables and after purchase behaviour: inter-realationship». Tourism Management. 22, pp. 607-616. 
BLAIN, C., LEVY, S.E. Y BRENT RITCHIE, J.R. (2005), «Destination Branding: Insights and Practices from Destination Management Organizations». Journal of Travel Research, 43, pp. 328-338.

BLAT, J. et al., (2001): Portal Inteligente de Promoción Turística. Universidad Pompeu Fabra. Barcelona. Disponible en: http://www.dtic.upf.edu/ tnavarrete/publications/ intermedia2001.pdf

BOYD, D. y ELLISON, N. (2007): «Social network sites: Definition, history, and scholarship». Journal of Computer-Mediated Communication, 13(1), pp. 210-230.

CASTELLÓ, A. (2010): «Una nueva figura profesional: el Community Manager». Pangea: revista de la Red Académica Iberoamericana de Comunicación, 1, pp. 74-97.

CASTELLÓ, A., y PINO, C.D. (2015): «Prescriptores, marcas y tuits: el marketing de influencia». Redmarka. Revista Académica Red de Marketing Aplicado, 8 (14), pp. 21-50.

CHATTERJEE, P. (2011): «Drivers of new product recommending and referral behavior on social network sites». International Journal of Advertising, 30 (1), pp. 77-101.

CHU, S. (2011): «Viral Advertising in Social Media: Participation in Facebook Groups and responses among college-aged users». Journal of Interactive Advertising, 12 (1), pp. 30-43.

CROMPTON, J. (1992): «Structure of vacation destination choice sets». Annals of Tourism Research, 19, pp. 420-434.

CROSS, R. y PARKER, A. (2004): The Hidden Power of Social Networks: Understanding How Work Really Gets Done in Organizations. Harvard Business School Press, Boston.

CURTY, R. y ZHANG, P. (2011): «Social commerce: Looking back and forward». Proceedings of the American Society for Information Science and Technology, 48 (1), pp. 8-10.

DELLAROCAS, C. (2003): «The digitization of word of mouth: promise and challenges of online feedback mechanisms». Management Science, 49 (10), pp.1407-1424.

DOYLE, P. (2003): Marketing Management and Strategy. Nueva York. Ed: Prentice hall.

EBY, D. et al. (1999): «Content Preferences for In-Vehicle Tourist Information System: An Emerging Information Source». Journal of Hospitality and Leisure Marketing, 6 (3), pp. 41-58.

FERNÁNDEZ, J. et al. (2014). Sitios web turísticos de las comunidades autónomas españolas. Proyecto Codetur. Universitat Pompeu Fabra, Barcelona.

FERNÁNDEZ, P. (2009): Clasificación de redes sociales. Disponible en: http://www. pabloburgueno.com/2009/03/clasificacion-de-redes-sociales/

FOLGADO, J. et al. (2012). «Imagen del destino y marca turística: sinergias e implicaciones». Tourism \& Management Studies, pp. 904-914.

FUNDACIÓN TELEFÓNICA (2014): La Sociedad de la Información en España 2013. Fundación Telefónica, Madrid.

GARCÍA, J. (2001): «Portales de internet: concepto, tipología básica y desarrollo». El Profesional de la Información, 10 (7-8), pp. 4-13.

GIRALDO, C. y MARTÍNEZ, S. (2015): Análisis de la actividad y presencia en redes sociales de las principales cadenas hoteleras y de los portales turísticos de las comunidades autónomas españolas. Trabajo fin de Máster, Universidad Politécnica de Cartagena, página web: http://hdl.handle.net/10317/5049 
GIRALDO, C. y SÁNCHEZ, N. (2014): Análisis de la actividad en redes sociales de marcas del sector moda: una aproximación al social commerce. Trabajo fin de Grado, Universidad Politécnica de Cartagena, página web: http://hdl.handle.net/10317/4192

GRETZEL, U. y YOO, K. (2008). «Use and impact of online travel reviews. In P. O'Connor, W. Höpken \& U. Gretzel (Eds)». Information and Communication Technologies in Tourism 2008, pp. 35-46.

GRUEN, T. et al., (2006): «eWOM: The impact of customer-to-customer online knowhow exchange on customer value and loyalty». Journal of Business Research, 59 (4) pp. 449-456.

HOSTELTUR (2008): «Un destino con marca, clave para una buena gestión del producto turístico». Hosteltur, página web: http://www.hosteltur.com/56206_destino-marcaclave-buena-gestion-producto-turistico.html

HUERTAS, A. (2014): Marca Turística o Marca de Destino. Proyecto ITOURIST, página web: http://www.marcasturisticas.org/index.php/definiciones/109-marca-turistica-omarc-de-destino

IAB Spain. (2013): «I Estudio Actividad de las marcas en medios sociales». Interactive Advertising Bureau Spain, Madrid.

IAB Spain. (2014): II Estudio Actividad de las marcas en medios sociales. Interactive Advertising Bureau Spain, Madrid.

IAB Spain. (2014): V Estudio Anual de Redes Sociales. Interactive Advertising Bureau Spain, Madrid.

IAB Spain. (2015): III Estudio Top 50 marcas en Redes Sociales. Interactive Advertising Bureau Spain, Madrid.

JIMENEZ, A. (2012): «Aclarando conceptos: Engagement en Comunicación». Puromarketing, página web: http://www.puromarketing.com/55/12033/conceptos-engagementcomunicacion.html

LAMBIN, J. et al. (2009). «Dirección de marketing: Gestión estratégica y operativa de mercado». Mc Graw Hill.

LIANG, T., y TURBAN, E. (2011): «Introduction to the Special Issue: Social Commerce: A Research Framework for Social Commerce». International Journal of Electronic Commerce, 16 (2), pp. 5-13.

LIBEROS, E. et al. (2010): El libro del comercio electrónico. ESIC Editorial, Madrid.

MARTORELL, O. y SERVERA, L. (2004). El impacto de las marcas en la industria hotelera del Reino Unido. Universitat de les Illes Balears, página web: http://www. esade.edu/cedit2004/pdfs/39_Martorell_Servera.pdf

MEMELSDORFF, F. (1998): «Marketing estratégico en turismo: branding, identidad y cultura corporativa». Revista Valenciana d'Estudis Autonòmics, 25, pp. 73-80.

MILLET, O.F. (2011): La imagen de un destino turístico como herramienta de marketing. Grupo Eumednet.

MURPHY, P. et al., (2000): «The destination product and its impact on traveller perceptions». Tourism Management, 21, 43-52.

OMT. (1995): «Collection of Tourism Expenditure Statistics». World Tourism Organization. Disponible en: https://pub.unwto.org/WebRoot/Store/Shops/Infoshop/Products/1034/1034-1.pdf 
OMT. (2014): «Panorama OMT del turismo internacional». Organización Mundial del Turismo. Disponible en: http://dtxtq4w60xqpw.cloudfront.et/sites/all/files/pdf/unwto_ highlights14_sp.pdf

ORDOZGOITI, R. y PÉREZ, I. (2003): Imagen de marca. ESIC Editorial. Madrid.

PIÑEIRO, M. (2012): «CCómo conseguir la mejor imagen de marca con las redes sociales?». Concepto 05 Agencia de marketing online, página web: http://www.concepto05. com/2012/04/como-conseguir-la-mejor-imagen-de-marca-con-las-redes-sociales/

POMBO, A. (2012): «Un nuevo concepto de portal turístico». MarketingData-Red.com. Disponible en: http://www.data-red.com/cgi-bin/articulos/ver.pl?id=201218276357

SANTO, C. (2014): «Redes sociales y móviles, las nuevas cartas de navegación de viajeros y turistas». Puromarketing.com. Disponible en: http://www.puromarketing. com/38/18284/sociales-moviles-nuevas-cartas-navegacion-viajeros-turistas.html

VERMEULEN, I. y SEEGERS, D. (2008): «Tried and tested: The impact of online hotel reviews on consumer consideration». Tourism Management, 30(1), pp. 123-27.

ZAGLIA, M.E. (2013): «Brand communities embedded in social networks». Journal of Business Research, 32(2), pp. 225-280. 